\title{
Biomarker-based Inflammatory Score in Obese Patients with Resistant Hypertension
}

\author{
Cibele Isaac Saad Rodrigues ${ }^{(0)}$ \\ Pontifícia Universidade Católica, São Paulo, SP - Brazil \\ Short Editorial relate to the article: Proposed Inflammatory Score of Circulating Cytokines/Adipokines Associated with Resistant Hypertension, \\ but Dependent on Obesity Parameters
}

Resistant arterial hypertension (RAH) is defined, according to the American Heart Association Scientific Position of 2018, ${ }^{1}$ as well as observed in the I Brazilian Position of RAH in 2012, ${ }^{2}$ when an individual's blood pressure (BP) remains elevated above the blood pressure target, in spite of the use of three antihypertensive drugs of different therapeutic classes, commonly a long-acting dihydropyridine slow-calcium-channel antagonist drug; a renin-angiotensin-aldosterone system (RAAS) blocker, which may be an angiotensin II converting-enzyme inhibitor or angiotensin II $\mathrm{AT}_{1}$ receptor blocker; and an appropriate diuretic, all administered at the maximum doses or at the highest possible tolerated doses, and in accordance with the prescribed administration intervals. These patients are considered to be at greater risk of cardiovascular and renal morbidity and mortality; ${ }^{3}$ more likely to have adverse events in response to drug therapy, usually dose-related; a secondary cause of hypertension should be ruled out in this group of individuals, because its prevalence is significantly higher than in the nonresistant hypertensive population. ${ }^{1,2}$ The controlled RAH is also currently recognized as that in which patients using four or more medications reached the blood pressure target; and refractory $\mathrm{AH}$, an entity that has a different pathophysiology from $\mathrm{RAH}$, when even the four drugs are not enough to control it. ${ }^{4}$ According to this new classification, patients with pseudohypertension should be excluded, that is, it is mandatory for diagnostic confirmation to verify adherence and tolerance to medication; to rule out white-coat hypertension; and thus, it is crucial to perform systematized blood pressure measurements outside the office environment through Ambulatory BP Monitoring (ABPM) or Home BP Measurement (HBPM); and finally, the use of a correct and reliable BP measurement technique. ${ }^{1,2,4,5}$

Even in primary $\mathrm{AH}$, the existence of a systemic inflammatory process, albeit a subclinical one, is recognized and this condition has been identified with higher intensity in cardiovascular and renal diseases, such as RAH and chronic kidney disease. ${ }^{6}$ Specifically in the case of RAH, which is a multifactorial and polygenic entity, often associated with metabolic diseases that occur with insulin resistance, such as diabetes and obesity, inflammatory processes promoted by mediators may be involved, leading to the important

\section{Keywords}

Hypertension/physiopathology; Obesity; Hypertension/adverse effects; CitoKyines; AdipoKynes; Biomarkers, Pharmacological.

Mailing Address: Cibele Isaac Saad Rodrigues •

Pontifícia Universidade Católica de São Paulo - Medicina - Rua Grécio

Scudeler, 61. Postal code 18048-006, Sorocaba, SP - Brazil

E-mail: cibele.sr@gmail.com

DOI: 10.5935/abc.20190051 endothelial dysfunction of the microvasculature and increased oxidative stress. ${ }^{7}$

Biomarkers, in turn, are quantifiable characteristics of the biological processes that can be measured with accuracy and reproducibility and may or may not correlate with clinical symptoms. ${ }^{8}$

In recent years, the search for these mediators that may be involved in the prediction, initiation, development, diagnosis, progression and follow-up of $\mathrm{AH}$ therapeutic efficacy has been intense and of great value, as the amount of knowledge increases.

Even in Brazil, a recent study has shown that patients with severe and uncontrolled $\mathrm{AH}$ have associated microvascular dysfunction, as well as high levels of C-reactive protein and endothelin (in patients not using statins). ${ }^{9}$

The article, "A Proposed Inflammatory Score of Circulating Cytokines/Adipokines Associated with Resistant Hypertension, but Dependent on Obesity Parameters" published in this issue, ${ }^{10}$ brings good news about the role of inflammatory cytokines and adipokines (TNF- $\alpha$, IL-6, IL-8, IL-10, leptin and adiponectin) that may be implicated in the pathophysiology of RAH. Based on the measurement of these biomarkers, it was possible to construct an inflammatory score that correlated more with the presence of overweight and obesity than with hypertension itself. The reason for these findings is possibly the production of these substances by the visceral adipose tissue, which becomes resistant to insulin and leptin causing immune responses that, in turn, activate inflammatory, prothrombotic and vasoconstriction cascades with sympathetic nervous system hyperactivity, sodium retention and RAAS activation, thus, occurring simultaneously with $\mathrm{AH}$ treatment resistance. ${ }^{11,12}$

The interest in the measurement of biomarkers can be very useful to understand all the variables of the hypertension phenomenon, particularly regarding its pathogenesis. ${ }^{7}$ It should be considered, however, that these measurements are not yet routinely available in clinical practice, not even in specialized AH centers, as they are expensive, have their use still restricted to research; have not been tested yet in a large scale survey from an epidemiological point of view; and require technical expertise so that their results are reliable. Understanding their roles, degrees of accuracy and reproducibility, as well as the correlation with cardiovascular and renal outcomes, is a task that still depends on future studies.

Despite the aforementioned difficulties, one can say we are moving towards the measurement of these biomarkers in a systematic way, as they gain more credibility and availability. Based on that, the construction of scores can help in the detection of situations of incipient inflammation, where it would be possible to perform early risk stratification with consequent timely interventions. 


\section{Short Editorial}

Therefore, it is expected we can better understand the pathophysiology of resistant hypertension in the presence of obesity and the biological phenomena that culminate in

\section{References}

1. Carey RM, Calhoun DA, Bakris GL, Brook RD, Daugherty SL DennisonHimmelfarb CR, et al. Resistant hypertension: detection, evaluation, and management: a scientific statement from the American Heart Association. Hypertension. 2018;72(5):e53-90.

2. Alessi A, Brandão AA, Coca A, Cordeiro AC, Nogueira AR, Feitosa AM, etal.. First brazilian position on resistanthypertension. Arq Bras Cardiol. 2012; 99(1):576-85.

3. Daugherty SL, Powers JD, Magid DJ, Tavel HM, Masoudi FA, Margolis KL, et al. Incidence and prognosis of resistant hypertension in hypertensive patients. Circulation. 2012;125(13):1635-42.

4. Muxfeldt ES, Chedier B, Rodrigues CIS. Resistant and refractory hypertension: two sides of the same disease? J Bras Nefrol. 2018 Dec 6. Pii:S0101- 28002018005045101.

5. Sheppard JP, Martin U, MacManus RJ. Diagnosis and management of resistant hypertension. Heart. 2017;103(16):1295-302.

6. de la Sierra A, Larrousse M. Endothelial dysfunction is associated with increased levels of biomarkers in essential hypertension. J Hum Hypertens. 2010;24(6):373-9. oxidative stress, inflammation and endothelial microvascular dysfunction. The study published in this issue contributes qualitatively to this understanding.
7. Shere A, Eletta O, Goyal H. Circulating blood biomarkers in essential hypertension: a literature review. J Lab Precis Med. 2017;2:99.

8. Strimbu K, TavelJA. Whatarebiomarkers?CurrOpin HIV AIDS. 2010;5(6):463-6.

9. Junqueira CLC, Magalhães MEC, Brandão AA, Ferreira E, Cyrino FZGA, Maranhão PA, et al. Microcirculation and biomarkers in patients with resistant or mild-to-moderate hypertension: a cross-sectional study. Hypertens Res. 2018;41(7):515-23.

10. de Faria APC, Ritter AMV, Gasparetti CS, et al. Proposta de um Escore Inflamatório de Citocinas e Adipocinas Plasmáticas Associado à Hipertensão Resistente, mas Dependente de Parâmetros de Obesidade. Arq Bras Cardiol. 2019; 112(4):383-389.

11. Chaudhary K, Buddinemi JP, Nistala R Whaley-Connell A.. Resistant hypertension in the high-risk metabolic patient. Curr Diab Rep. 2011;11(1):41-6.

12. DeMarco VG, Arooor AR, Sowers JR. The pathophysiology of hypertension in patients with obesity. Nat Rev Endocrinol. 2014;10(6):364-76. 